\title{
Conceptualising the mortality divide in Germany: towards an interdisciplinary analysis
}

Why should we know about trends in mortality? Simply, because we want to control them as life expectancy is considered the most relevant health indicator. And here the trouble starts: there are too many determinants affecting health in different combinations at different historical times. During the cold war the "big simplifiers" used every information to argue in favour of either one system completely ignoring the complexity of the issue. After 1989 the collapse of the Soviet system seemed to prove the superiority of the Western model of health care-especially to Germans on both sides of the former Iron Curtain. However, it is difficult, at the least to say, to compare a system operating with extremely limited financial means to another one having enough resources to waste them abundantly. The features of the German Democratic Republic (GDR) system of health care has never got a chance to be tested under the more favourable economic conditions after the change of 1989 , in Germany referred to as the "Wende".

Several hypotheses have been brought forward to explain the gap in life expectancy between Eastern and Western Europe that has been widening since the 1970s. These hypotheses include in addition to the allocated budgets the availability of high-tech medicine, the quality of nutrition, the differing consumption patterns for alcohol and tobacco, the degree of environmental pollution, the East to West migration preferably of the younger ones. ${ }^{1}$ All of these and more being unequal we are left with the difficult question of what the contribution of the differing systems of health care may have been? One of the most prominent characteristics was the provision of ambulatory care through independent practitioners in the West versus polyclinics and dispensaries in the East. The magnitude of change after re-unification in the former GDR can be appreciated by looking at the percentage of free practising physicians of all doctors in ambulatory care: from 35\% in 1965 only $2 \%$ were left by the end of the $1980 \mathrm{~s}^{2}$ compared with about $90 \%$ nowadays, similar to the situation in the so called old federal states of Germany. Another figure may be of equal interest, in the late GDR the percentage of practising female physicians was around $70 \%$, it is expected to be half of this in the future. The fate of female doctors after unification in the city of Cottbus has been described in a moving analysis by Lützenkirchen. ${ }^{3}$ The situation gets complicated even more when taking into consideration that there has always been a West-East or rather a South-West to North-East gradient in Europe as well as within Germany. For example, between the West German states life expectancy differs by more than two years for men and more than 1.5 years for women between Baden-Würtemberg in the South-West and Bremen in the North.

The two papers by Nolte et al published in this issue are the first to comprehensively and in detail treat the intricate effects of the political and socioeconomic transition in the eastern part of Germany on mortality. Ten years after re-unification this is probably the earliest moment such analysis could meaningfully be performed. The observational nature of information from this huge "natural" experiment limits intellectual scrutiny to plausibility and denies definite assurance on causality. However, with this caveat we may reasonably safely conclude, that all possible effects of the transition process taken together are the cause of an improvement in life expectancy much better than expected. Actually the quickness of positive change has even aroused scepticism and certainly restricts the spectrum of possibly causal determinants to those exercising their impact relatively short-term such as psychosocial reactions, curative medical advancement, or certain nutritional changes symbolised by bananas that suddenly became available en masse for East Germans. With regard to the latter, for instance, clear differences in urinary excretion of potassium ${ }^{5}$ have been described between the two parts of Germany relating to the period before 1989 . Another interesting aspect is the lower incidence of allergic diseases in the former GDR now nearing towards the western levels. ${ }^{6}$

The approach of the authors to compare developments in the eastern states of Germany not only with the western "Laender" but also with the other neighbour Poland strengthens the interpretations offered in many ways. A more rigid multivariate analysis including more if not all countries of central and eastern Europe admittedly depends on the availability of reliable and comprehensive data. However, the historical uniqueness of the events of 1989 permits for the first time a thorough analysis of an almost complete spectrum of possible factors affecting mortality in industrialised nations that must not be missed. The German-German-Polish comparison alone may not allow for sufficient variance to explain the many divergent and contradictory developments in subgroups for sex and age in a satisfactory way.

As important as it is to establish the facts I think this is clearly an issue where the epidemiological reasoning has to be blended with sociological theories of change.

The fascinating task for future research may be to relate the modification of social organisation to changes in health status also at the micro-level. This necessitates an interdisciplinary approach as offered in the health sciences including, for example, health psychology, health economics, health sociology and last but not least the political sciences.

ULRICH LAASER

Faculty of Health Sciences, University of Bielefeld, PO Box 1001 31, D 33501 Bielefeld, Germany

Correspondence to: Professor Laaser (u.laaser@health.ibs.uni-bielefeld.de)

1 Laaser U. German health policies in the years of change. In: Laaser U, Stock $\mathrm{Ch}$, eds. Public health in Eastern Europe, status and priorities. $\mathcal{F}$ Publ Health Ch, eds. Public health

2 Sachverständigenrat für die Konzertierte Aktion im Gesundheitswesen, ed. Fahresgutachten: Das Gesundheitswesen im vereinten Deutschland. BadenBaden: Nomos-Verlagsgesellschaft, 1991.

3 Lützenkirchen A. "Ich wäre so gern wieder Mediziner!" Die Veränderung der beruflichen Situation von Ärztinnen in den neuen Bundesländern. Lage: Verlag Hans Jacobs, 1999.

4 Statistisches Bundesamt, ed. Gesundheitsbericht für Deutschland: Gesundheitsberichterstattung des Bundes. Stuttgart: Metzler-Poeschel, 1998.

5 Intersalt-Forschungsgruppe aus BRD und DDR (Heinemann L, Hofmann $\mathrm{H}$, Laaser U, et al). Blutdruck, relatives Körpergewicht, Alkoholkonsum und Elektrolytausscheidung in der BRD und der DDR: Die IntersaltStudie. Klin Wochenschr 1990;68:655-63.

6 Weiland SK, von Mutius E, Hirsch T, et al. Prevalence of respiratory and atopic disorders among children in the East and West of Germany five years after unification. Eur Respir ₹ 1999;14:862-70. 